\title{
Transformation of hydrophobic flavonoids catechin, dihydroquercetin and quercetin into water-soluble structures
}

\author{
Alexander M. Koroteev, ${ }^{1}$ Garry Z. Kaziev, ${ }^{1}$ Mikhail P. Koroteev, ${ }^{1 *}$ Anna F. Stepnova, ${ }^{1}$ \\ Anton O. Pozdeev, ${ }^{1}$ Valery P. Zinchenko, ${ }^{2}$ Alexander I. Sergeev, ${ }^{2}$ and Evgeny N. Ofitserov ${ }^{3+}$ \\ ${ }^{1}$ Department of Organic Chemistry. Institute of Biology and Chemistry. Moscow \\ Pedagogical State University. Kibalchicha St., 6, Bldg. 2. Moscow, 129164. Russia. \\ Phone: +7 (495) 682-02-45.E-mail: starmansky@mail.ru \\ ${ }^{2}$ Institute of Cell Biophysics FGBUN "Federal Research Center "Pushchino Scientific Center \\ for Biological Research RAS”. Institutskaya St., 3. Pushchino. Moscow Region, 142290. \\ Russia.Phone: +7 (916) 235-48-95.E-mail:vpz@mail.ru \\ ${ }^{3}$ Department of Chemistry and Technology of Biomedical Preparations. Faculty of Chemical \\ and Pharmaceutical Technologies and Biomedical Products. Russian University of Chemical \\ Technology D.I. Mendeleev. Miusskaya Sq., 9. Moscow, 125047. Russia. \\ Phone: +7 (495) 978-32-61.E-mail: ofitser@mail.ru
}

\section{*Supervising author; ${ }^{+}$Corresponding author}

Keywords: acylation, flavonoids, dihydroquercetin, catechin, quercetin, $\beta$-cyclodextrin, L-arginine, hydrophobicity, water solubility, guest-host complexes.

\section{Abstract}

The paper describes methods for the transformation of poorly water-soluble flavonoids: dihydroquercetin, catechin and quercetin into water-soluble forms during the formation of supromolecular adducts with $\beta$ cyclodextrin and salt-type ionic complexes with the natural amino acid L-arginine, which contains a guanidine moiety properties necessary to create a cationic structure when interacting with phenolic groups.

First, a methodology was developed for the synthesis of supromolecular structures, in which flavonoids were incorporated into a cyclodextrin matrix. As a result, the solubility in water at $20{ }^{\circ} \mathrm{C}$ of encapsulated flavonoids increased by more than two orders of magnitude. In the formation of complexes of cyclodextrin with flavonoids, the main role is played not by hydrogen bonds between the hydroxyl groups of flavonoids and $\beta$-cyclodextrin - in the case of dihydroquercetin and catechin, they are different and similar in the case of dihydroquercetin and quercetin, but the spatial orientation of the pyrocatechol cycle B (due to the flat conjugation of the entire molecule and due to $s p^{2}$ is the structure of the second carbon atom of the pyran ring).

Another implemented approach for obtaining water-soluble flavonoids at room temperature is the creation of their salts with the natural amino acid L-arginine, which is a part of proteins and is involved in several vital processes in the body.

The structure of the obtained compounds was proved by the methods of NMR spectroscopy on ${ }^{13} \mathrm{C}$ nuclei and X-ray structural analysis, the composition - by elemental analysis.

\section{References}

[1] V.S. Rogovskiy, A.I. Matyushin, N.L. Shimanovskiy, A.V. Semeykin, T.S. Kukhareva, A.M. Koroteev, M.P. Koroteev, E.E. Nifant'ev. Antiproliferative and antioxidant activity of new dihydroquercetin derivatives. Experimental and Clinical Pharmacology. 2010. No.9. P.39-42. (russian)

[2] E.E. Nifant'ev, M.P. Koroteev, T.S. Kukhareva, A.M. Koroteev, N.M. Pugasheva, S.E. Mosyurov, N.M. Kutuzova, G.Z. Kaziev. Chemical modification and biological activity of the flavonoid dihydroquercetin. Science and school. 2012. No.6. P.181-191. (russian)

[3] M.N. Zaprometov. Biochemistry of catechins. Moscow: Science. 1964. (russian)

[4] H.K. Nair, K.V. Rao, R. Aalinkeel, S. Mahajan, R. Chawda, S.A. Schwartz. Inhibition of prostate cancer cell colony formation by the flavonoid quercetin correlates with modulation of specific regulatory genes. Clinical and Diagnostic Laboratory Immunology. 2004. Vol.11. P.63-69.

[5] R.H. Böger. The pharmacodynamics of L-arginine. J. Nutr. 2007. No.137. P.1650-1655.

[6] M.K. Grachev, V.I. Maslennikova, M.P. Koroteev, E.N. Rasadkina. Organic chemistry in Moscow. Journal of Gen. Chem. 2018. Vol.54. No.2. P.322-338. (russian) 
TRANSFORMATION OF HYDROPHOBIC FLAVONOIDS CATECHIN, DIHYDROQUERCETIN AND QUERCETIN... 14-21

[7] A.M. Koroteev, G.Z. Kaziev, M.P. Koroteev, E.E. Nifant'ev, V.M. Shutov. Water-soluble inclusion complex dihydroquercetin- $\beta$-cyclodextrin and method for its preparation. RF patent for his invention № 2396070. Registered in the State Register of the Russian Federation on 08.10.2010. (russian)

[8] A.M. Koroteev, G.Z. Kaziev, M.P. Koroteev, A.T. Teleshev, V.P. Zinchenko. Water-soluble pharmaceutical composition L-arginine-dihydroquercetin and method for its preparation. RF patent for invention №2545905. Registered in the State Register of Inventions of the Russian Federation on February 26, 2015. (russian) 